\title{
Enhanced oil recovery with carbon dioxide geosequestration: first steps at Pre-salt in Brazil
}

\author{
José Maria Alves Godoi ${ }^{1}\left[\right.$ D Patrícia Helena Lara dos Santos Matai ${ }^{1}$
}

Received: 15 May 2019 / Accepted: 25 January 2021 / Published online: 15 February 2021

(c) The Author(s) 2021

\begin{abstract}
This paper revisits the intense using of energy in the world and the role of the fossil fuels with predominance of the oil in the global primary energy supply and their effects to climate change. It also presents a new reading on the thermodynamic conditions and characteristics of $\mathrm{CO}_{2}$ and $\mathrm{CO}_{2}$-EOR together with oil industry advancement in the world and Brazil. The interface with chemical EOR processes involving nanoparticles (NPs), their application inside the reservoirs for EOR and understanding of fines migration reducing, among other physical phenomena is also studied. Carbon capture and storage (CCS) is a worldwide strategy for mitigating climate change. $\mathrm{CO}_{2}$ geosequestration is also analyzed on the leakage of $\mathrm{CO}_{2}$ and brine from aquifers and their implication to the security of the storage and environment. Recent studies show that, globally, $\mathrm{CO}_{2}$-EOR can extract up to 375 billion of additional oil barrels and geological storage up to $360 \mathrm{Gt}$ of $\mathrm{CO}_{2}$ in the next 50 years. Pre-salt is a complex of microbial carbonate reservoirs with stromatolite framework in ultra-deep waters (1500$3000) \mathrm{m}$ depth, underneath by thick salt layer (2000-2500) $\mathrm{m}$. Its reservoirs are in the depth up to (5500-6500) $\mathrm{m}$ TVDSS and approximately (200-300) km offshore. It presents light oils and high (GOR) ranging (200-400) $\mathrm{Sm}^{3} / \mathrm{Sm}^{3}$ and huge $\mathrm{CO}_{2}$ contamination (8-15)\%. Due to the large $\mathrm{CO}_{2}$ content of oil, this work investigated $\mathrm{CO}_{2}-\mathrm{EOR}$ and $\mathrm{CO}_{2}$ geosequestration within the reservoirs. Pilot test demonstrated that miscible $\mathrm{CO}_{2}$-EOR with WAG is feasible and beneficial to this hydrocarbon Province. This study also calculated and validated the potential of $\mathrm{CO}_{2}$-EOR to the CCS. It concludes that Pre-salt can contribute to recovery factor (RF) increasing about 5.7 billion of additional oil barrels, and to CCS with about $266 \mathrm{Mt} \mathrm{CO}_{2}$ to be geological stored, for the next 20 years. In this context, this work also analyses the recent changes on the Brazilian oil and gas regulation to encourage new international Companies to enter in Brazil and Pre-salt for petroleum exploring. In Pre-salt, $\mathrm{CO}_{2}$-EOR also connects the petroleum energy system to CCS, transforming the oil reservoir in a carbon sink. These results represent a substantial role of Pre-salt to the energy efficiency of energy resources recovering from the biosphere and a high contribution to the climate change mitigation.
\end{abstract}

Keywords Pre-salt $\cdot$ Additional oil $\cdot \mathrm{CO}_{2}$ geosequestration $\cdot$ Climate change

\section{Introduction}

Energy is the main anthropogenic forcing of climate change (Goldenberg and Lucon 2008; IPCC 2014). Broad and complex studies demonstrate that global warming accounts for the thermodynamic equilibrium rupture inside the greenhouse where the Earth inhabits with numerous forms of life. The climate change is driven by the global anthropogenic

José Maria Alves Godoi

godoi@godoienergia.com.br

$1 \quad$ Escola Politécnica, Mines and Petroleum Engineering Department, University of São Paulo, 2373 Prof. Mello Moraes Av., Butantã, São Paulo, SP 05508-900, Brazil greenhouse gas (GHG) emissions. The most important GHG is $\mathrm{CO}_{2}$, constituting approximately $76.7 \%$ of the total emissions; the remaining $22.3 \%$ are composed of methane, nitrous oxide, and fluorine gases.

The main reason for the more aggressive GHG emissions is the intense and global use of the fossil fuels, which currently reach $81.3 \%$ of the worldwide energy supply, and petroleum has the global dominance with share of $31.6 \%$ to the total primary energy supply in the world, followed by coal $(26.9 \%)$ and natural gas $(22.8 \%)$. Therefore, it is exhibited the predominance of fossil fuels in the world energy supply, typifying them as the highest global GHG emitters on the surface level. Regarding to GHG emissions, oil is the second most important global emitter, with

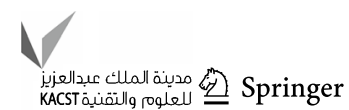


$34.1 \%$ of the total world $\mathrm{CO}_{2}$ emission by fuel, immediately after coal, which reaches $44.0 \%$; both are the main global GHG emitters, followed by natural gas (21.2\%). Thus, nowadays fossil fuels present the most contribution about $33.5 \mathrm{Gt} \mathrm{CO}_{2}$ emission to the atmosphere (IEA 2020).

According to long-term analysis of the worldwide energy trends (adopting its new policies scenario as central scenario), International Energy Agency (IEA) forecasts for 2040 on demand side alone, that fossil fuel share will reach approximately $74.0 \%$, and oil will again have the largest share of $27.6 \%$ (equivalent to 4894 Mtoe) and will be the higher among all energy sources. Regarding to present, these data indicate a worldwide decline of the total oil share in the long term $(40.8 \% / 27.6 \%)$, with a continuous increase in its absolute amount of demand, which will be equivalent to 4055 Mtoe/4894 Mtoe) (IEA 2018, 2020).

The global concerns for the energy access growth and energy security and role of fossil fuels and their implications on climate change are rising. Concerning oil, for each barrel no longer used in the Organization for Economic Co-operation and Development (OECD) countries, two others are used in non-OECD ones. Increased oil use for transport and petrochemicals will increase its demand from 95 million barrels per day $(95 \mathrm{Mb} / \mathrm{d})$ in 2017 to $106 \mathrm{Mb} / \mathrm{d}$ in 2040, although high prices and new policy measures gradually constrain the rate of overall consumption growth, bringing it toward a plateau.

This predominance of fossil fuels in the global primary energy supply and demand already considers the intensification of renewable sources and energy-efficient programs in advancement, which have mostly employed in the OECD countries. These countries and the associated programs face decisive and additional issues such as progressive social awareness of the socio-environmental problem on the climate change, resulting in new combined environmental and energy policies, industrial restructuring with consequences in the reduction in fossil fuels use, and the development of carbon capture and storage (CCS) policies. Regarding to CCS, newly developed carbon use techniques have been validated with relevant results. This has led to carbon capture, use and storage (CCUS) as well as $\mathrm{CO}_{2}$-EOR. Together with the intensification of use of renewables and achievement of energy efficiency, CCS is the third most important global policy to mitigate climate change.

Since 1970s, $\mathrm{CO}_{2}$-EOR has been applied specifically to increase the recovery factor (RF). Recent technologies allow this traditional practice to aggregate a new situation and value besides increasing RF: the geological storage (geosequestration) of $\mathrm{CO}_{2}$ within the reservoir. This geosequestration process aims to maximize its both advantages: the amount of oil extracted and the amount of $\mathrm{CO}_{2}$ geological stored instead to releasing it to the atmosphere.
In this way, recent study about EOR potential within Iran chooses 11 (eleven) candidate Iranian reservoirs and summarizes screening criteria and screening algorithms for discussion and elaboration on accuracy in the EOR screening, comparing the parameters of the candidate reservoirs with the criteria ranges, stablishing quantitative basis for comparison and classifying the importance of these parameters for many EOR methods. This study yet assigns weight system for these parameters and defines cutoffs (Mashayekhizadeh et al. 2014). These authors yet make a careful summary on steps for screening of EOR projects, considering aspects regarding to technical, economic and site selection, besides estimation of recovery factor (RF) based on empirical correlations, simple models and software.

Supported by analysis on approach of optimistic and pessimistic criteria extracted from collected criteria and their application on eleven chosen reservoirs involved in the study (considering detailed parameters regarding to geologic and fluid characterizations of reservoirs), the authors conclude that miscible $\mathrm{CO}_{2}$ and hydrocarbon gas injections are both promising mechanisms for those referred reservoirs.

Pre-salt Province in Brazil is recognized as the biggest set of giant oil fields recently discovered in the world. Its most reservoirs are estimated to reach extraction volumes of billions barrels of oil described as follows. Nowadays, about only 13 years of its exploration beginning, the Province already is responsible for about $70.3 \%$ of the total Brazilian oil extraction, representing 2.739 million barrels of oil equivalent per day (2.739 Mboe/d) (ANP 2020). There is few time the national legislation and regulation for the oil and gas sector are changed, with broad permission to regimes of concession and production sharing in the country. Since these new rules, many bidding rounds for oil and gas exploration in Brazil are already made. In this new competitive view, many international Companies, such as British Petroleum, Total, Equinor, among others, are arriving for exploring Pre-salt and starting their extraction strategy and processes.

In this context, many scientific articles and reports on reservoir engineering are being published. If Pre-salt is known by geological research and publications, now it is additionally being understood by reservoir and drilling engineering.

Thus, this paper revisits the intense using of energy in the world and the role of the fossil fuels with predominance of oil in the global primary energy supply and their effects to climate change. It also presents a new reading on the thermodynamic conditions and characteristics of $\mathrm{CO}_{2}$ and $\mathrm{CO}_{2}$-EOR together with oil industry advancement in the world and Brazil. It is yet made an interface of this EOR method with chemical EOR processes, involving nanoparticles (NPs) and their application inside the reservoirs for EOR. About $\mathrm{CO}_{2}$ geosequestration also, there is analysis on the leakage of $\mathrm{CO}_{2}$ and brine from aquifers and their 
implication to the security of the storage and environment. The new and decisive role of $\mathrm{CO}_{2}$-EOR to CCS is also analyzed and demonstrated. Afterward, the work introduces Pre-salt Province in Brazil and describes on the evolution and nature of this large hydrocarbon Province, highlighting on their geology and reservoir and fluids characteristics; and through pilot test is shown the application and benefits of the $\mathrm{CO}_{2}$-EOR with WAG in the Province. Finally, it is calculated and validated the potential of the RF increasing and the $\mathrm{CO}_{2}$ geosequestration in Pre-salt. This paper also pursues to advance on technology development in offshore oil exploration to provide scientific information with novel developments among researchers and engineers.

\section{Brief revisit on the $\mathrm{CO}_{2}, \mathrm{CO}_{2}$-EOR and oil industry advancement in the world and Brazil}

The most important physical behavior for the efficiency of the $\mathrm{CO}_{2}$-EOR is the miscibility of the $\mathrm{CO}_{2}$ with the oil phase, because at pressures higher than the minimum miscibility pressure (MMP), immediately greater than critical point on the bimodal curve and starting from this point, oil and $\mathrm{CO}_{2}$ are mutually soluble (Blunt et al 1993; Orr Jr and Taber 1984). Miscibility implies that the capillary forces (interface phenomenon) between the fluids are removed, forming a homogeneous phase, producing the best mechanical interaction between them. Miscibility conditions between $\mathrm{CO}_{2}$ and oil are essential for increasing ("to repair") the thermodynamic potential of the reservoir to remove residual oil. This thermodynamic potential obtained by the pressure $(P)$, temperature $(T)$ and chemical potential $(\mu)$ of the present chemical species-compound $(n)$. After the primary and/ or conventional secondary recovery, this potential suffers depletion. It is vital "to rectify" this thermodynamic potential $(P, T, \mu)$ of the reservoir to regenerate the suitable conditions for the energy conversion processes required to remove the interfacial tension, producing complete mechanical interactions between the fluids and increasing the capacity to push out the residual oil throughout reservoir (Godoi 2015).

This "repair" of the thermodynamic potential occurs simultaneously with the following effects: (1) creation of a secondary gas cap or enlargement of an existent primary gas cap; (2) gas cycling occurrence, improving the RF from condensate reservoirs by vaporizing the fluids that eventually condense within the reservoir for steeply dipping reservoirs. Because $\mathrm{CO}_{2}$ injection at the crest of the structure also helps oil displacement toward to wells. As result, the volumetric sweep efficiency can be high because of these mechanisms. Therefore, miscibility is decisive for the significant improvement in the residual oil displacement capacity of the system. For the best control of the gravity override and viscous fingering, with the early gas breakthrough, $\mathrm{CO}_{2}$ injection alternating with the water-gas, that is, water-alternating-gas (WAG) process is a recognized effective strategy to be used.

To reach miscibility, $\mathrm{CO}_{2}$ has to operate at supercritical conditions $(P \approx 1.100$ psia; $T>304 \mathrm{~K})$. Under such miscibility conditions, $\mathrm{CO}_{2}$ accomplishes fluid characteristics and similar intensive properties of changing to a liquid-like behavior toward lighter components of the oil. Fortunately, typical reservoirs operate in the thermomechanical potential range, in which $P>1000 \mathrm{psia}$ and $294 \mathrm{~K} \leq T \leq 394 \mathrm{~K}$. Usually, reservoir temperatures are in the $\mathrm{CO}_{2}$ supercritical temperature region $(T>304 \mathrm{~K})$. This is the first advantage of $\mathrm{CO}_{2}$ relative to other options of solvents such as air, dry natural gas, $\mathrm{N}_{2}$ and LPG.

$\mathrm{CO}_{2}$ has other advantages in comparison with these mentioned solvents, such as dry natural gas and LPG have a considerable market value, representing a high competition for EOR applications; owing to its representation in the climate change issue, $\mathrm{CO}_{2}$ must be captured and treated and delivered to EOR activities. This gas presents a relatively low compressibility factor and regarding to that other options of solvents, it exhibits a higher density and lower specific molar volume. $\mathrm{CO}_{2}$ density is not only higher, but is also much closer to the typical oil density, what implies to be more predisposed to miscibility and much less to gravity segregation during the displacement. In the aforementioned thermomechanical potential range of typical reservoirs, the viscosities of natural gas, LPG, flue gas, air and $\mathrm{N}_{2}$ are approximately the same, whereas $\mathrm{CO}_{2}$ viscosity is usually twice or thrice higher than their values. This last characteristic implies that $\mathrm{CO}_{2}$-crude oil mobility ratio will be twice or thrice smaller than that of the solvents, what results in a volumetric sweep efficiency with $\mathrm{CO}_{2}$ generally better (Lake 2010).

When there is a high-water saturation, usually, there is an equivalent increase in the gravity segregation because $\mathrm{CO}_{2}$ has a higher segregation with water than with oil; even if this effect is not total favorable for pushing out the residual oil, it is highly preferable for $\mathrm{CO}_{2}$ geosequestration. Therefore, if the purpose is to do $\mathrm{CO}_{2}$-EOR with geological storage of $\mathrm{CO}_{2}$, it is necessary to counterbalance these $\mathrm{CO}_{2}$ characteristics.

Miscible $\mathrm{CO}_{2}$-EOR with WAG is considered relevant for best performance of this special secondary recovery method, including $\mathrm{CO}_{2}$ geosequestration within the reservoir. This compose process also requires to combine the percentage of pore space filled with water and with $\mathrm{CO}_{2}$ together with the use of pure $\mathrm{CO}_{2}$ about after of half of the oil in place has been recovered. This balance of pore space occupation and pure $\mathrm{CO}_{2}$ injection also requires a well control management for shifting excessive $\mathrm{CO}_{2}$ extraction and control increasing of reservoir pressure. The combining of these parameters and the time is crucial to the optimization of both targets: 
optimize the amount of oil recovered and of $\mathrm{CO}_{2}$ geological stored inside the reservoir (Kovscek and Cakici 2005).

In the sense of micelles formation and oil swelling for helping the performance of $\mathrm{CO}_{2}$-EOR and the evidence of nanoparticles (NPs) use is increasing in the field of petroleum engineering, recent study reviews and discusses on the interactions of NPs with low salinity water (LSW) and surfactant for enhanced oil recovery (EOR) in sandstone and carbonate reservoirs. This study had analyzed the critical role of the interactions forces in the oil recovery process when NPs are injected together with surfactant inside the reservoir and the influencing mechanisms on the interfacial tension (IFT). It had also investigated the influencing mechanisms to the wettability of the rock and reducing oil-water IFT, and the basic screening criteria for the injection of NPs with LSW or surfactant into the reservoir (Olayiwola and Dejam 2019a).

These investigations had demonstrated that the effectivity of NPs to reduce fines migration during LSW injection into the reservoir depends on the type of reservoir, its brine composition and the effective charges of the NPs in solution. Besides these characteristics, the increasing of NPs in deionized and low and high salinity water with its consequences in the variation of the contact angle and its final influence on the recovery factor (RF) of oil had been validated. Together with these evidences, the action of surfactants for improving the stability of NPs in solution and reduction in IFT by the effective charges of the ions of these NPs and surfactant, and the behavior of IFT of solutions of LSW, surfactant and contact angle, when the salinity of the solution is increased were also proven.

Although the increase in using of NPs in the chemical process of EOR, this referred review recommends its accurate combination with these NPs, LSW and surfactant when they are injected into the reservoir. If there is careful for the best option of different combinations of these elements during injection, their significance on the variation in contact angle, the stability of NPs and the IFT can bring a great result to improve EOR process in sandstone and carbonate reservoirs.

In their research on application of NPs inside the reservoirs for EOR and understanding fines migration reducing, these authors also developed a mathematical modeling (a proposition of theoretical model) of surface tension of NPs with and without electrolyte solutions, delineating the effects of NPs in deionized water and brine on the surface tension. For constructing this model, the authors had begun at previous studies, using appropriate and recognized literature about the phenomena. According to experimental analysis, the proposed theoretical model by the authors had proven that, at the same time its congruence with the reported data in the recognized literature, it can determine the change in surface tension of NPs in deionized water for different sizes of NPs. This study yet concludes that Van der Waals interaction can causes deviation in the experimental data at high concentrations of NPs and electrolytes. As the proposed model is already used to determine the surface tension of both NPs in deionized water and NPs in brine, it can bring an important contribution to the current simulators for a precise prediction of the reservoir performance (Olayiwola and Dejam 2019b).

Inside this interface between water compositions, chemical EOR and $\mathrm{CO}_{2}$-EOR methods, late experiences indicate the importance of control on salinity and composition concerning the low salinity (LS) waterflooding to some EOR methods. In this way, another recent work recognizes the implications of any basic dimensions of reservoir engineering, such as pore size and geometry, wetting specifics, surface and interfacial tension (IFT) of the rock-fluids system on the capillary forces within the petroleum reservoir. This work had also analyzed the role of fluid-fluid interaction during low salinity waterflooding (LSW), supplies mechanistic study with novel experiments examining the behavior of the fluid in a single pore when brine solution comes into contact with crude oil. The work also involves to recognize the existence of asphaltene aggregates at the oil-brine interface in different brine solutions to find an accepted interpretation by regarding IFT results and, according to the experiments made, to investigate the formation of water micro-dispersions in the synthetic oil due to the synthetic oil-brine interaction (Rostami et al 2019). These authors had investigated the LS effect on the fluid-fluid and rock-fluid interactions and examine visually how the oil-water interface would be affected by asphaltene concentration through changing brine salinity. Experience was also conducted to clarify about the mechanism behind alteration of IFT by LS water injection and analysis was also performed using a wide range of brine salinity so as to test out the salinity range at which these changes can be observed.

By mean of such study, the authors performed discussion about different salinity mechanisms and had verified in the range between two and ten times diluted sea water (2SW and 10SW), and the effect of this low salinity water on wettability changing is more significant compared to high salinity water. It had also observed, as a result of aging the solid surfaces in the interval between two and ten times dilutes seawater, the change of wettability from oil-wet to water-wet and to strongly water-wet, and yet the reducing of IFT values for two times diluted seawater when compared to other brines for both crude oil and synthetic oil. Microscopic experiences of brine injection had also demonstrated when cations concentration near the interface, in the cases of sea water and formation water injections, the surface active asphaltenes are transferred back to the oil phase and depleted near the interface causing high IFT value. Whereas when deionized water and 10SW were injected, adsorption of the 
asphaltenes into the interface was very low. The formation of water micro-dispersion within the oil phase depends on oil properties, thermodynamic potential (pressure and temperature) conditions and so forth.

The chemical analysis above is important to have a view on the salinity and composition of water injection, IFT behavior, etc. However, due to its offshore and geographic location with large distance from the shore and their implications in logistics and additional technical and economic risks and great difficulties to install plants for chemical fluids injection, the chemicals EOR methods were considered unfeasible in Pre-salt, mainly at Santos Basin.

In this process of understanding Pre-salt and its opportunities of $\mathrm{CO}_{2}$-EOR and the connection between this EOR method and CCS as above mentioned, it is necessary to do any discussion on some physical characteristics of $\mathrm{CO}_{2}$ geosequestration and its behavior about $\mathrm{CO}_{2}$ and brine leakage from an aquifer. In this way, the diffusive leakage of brine from a storage aquifer as result of $\mathrm{CO}_{2}$ geosequestration into overlying and underlying low permeability layers, recent study developed a theoretical model, which was also evaluated according to field studies at two potential sites in United Kingdom (Dejam and Hassanzadeh 2018a). Due to usual injection under subsurface supercritical conditions, $\mathrm{CO}_{2}$ is less dense and less viscous then the resident aquifer brines. Under these thermodynamic conditions, $\mathrm{CO}_{2}$ migrates upward and spreads laterally under an overburden, which increases the risk of $\mathrm{CO}_{2}$ and brine leakage into overlying regions through faults, fractures, or leak wells. Thus, this issue on leakage of $\mathrm{CO}_{2}$ and brine from deep storage reservoirs is essential because the leakage of the gas is a major risk factor consequent from its geosequestration.

Their model was made on two-dimensional domain formed by an aquifer and an overburden, where the interaction between the two media is handled by imposing the continuities of pressure and fluid fluxes at the aquifer-overburden interface. The study shows the behavior of diffuse leakage rate at early and late times; the variation of the average pressure in the aquifer at short and long times. The increasing of the average pressure in the overburden with lower slope at late times and its comparison to the one at early times during diffuse leakage of brine from the storage aquifer into the overlying layer is also estimated. The field studies permitted to evaluate the variations of the diffuse leakage from the aquifer into overburden regarding times after injection for both sites in United Kingdom.

In the complete study, it was found the physical agents that influence leakage rate through overburden during $\mathrm{CO}_{2}$ injection, which are here listed in decreasing order of significance: (1) thickness of overburden; (2) thickness of aquifer; (3) aquifer to overburden permeability ratio; (4) aquifer to overburden porosity ratio. In this sequence of evidences, the authors also concluded that thickness of aquifer has minimal effect on diffusive leakage of brine within post injection period.

In this core on leakage of brine from an aquifer as resulting of geologic storage of $\mathrm{CO}_{2}$, another study investigates the diffusive leakage rate (DLR) of brine from a finite fractured (double porosity) aquifer. This study also uses a twodimensional domain, handling the interaction between aquifer and caprock, continuities of pressures and fluid fluxes into account at aquifer-caprock interface (Dejam and Hassanzadeh 2018b). As above aroused, this theme also refers to environmental concern associated with $\mathrm{CO}_{2}$ geosequestration and regards to its leakage from the storage aquifers through fractures, faults, leaky wells and overlying geologic structures to the atmosphere.

The authors demonstrate that when the ratio of the horizontal fracture to the caprock permeabilities $\left(k_{\mathrm{fh} 1 \mathrm{D}}\right)$ is small, the double porosity parameters during $\mathrm{CO}_{2}$ injection influence DLR of brine and the average pressure in the aquifer and the caprock. Whereas, when the contrary occurs, that is, $k_{\mathrm{fh} 1 \mathrm{D}}$ is large, there is not the mentioned influence on the DLR of brine and the average pressure in the aquifer and the caprock. The investigation also indicates that in the post-injection period, if it is found a low to moderate $k_{\text {fh1D }}$, DLR of brine is negligible, but if there is a large $k_{\mathrm{fh} 1 \mathrm{D}}$, DLR is accounted and evident. This study is still considered as a tool of significance to be applied to geosequestration of $\mathrm{CO}_{2}$ in fractured saline aquifers.

On the view of significance of EOR- $\mathrm{CO}_{2}$ to the climate, the IEA reference technology scenario (RTS) that takes into account energy (and climate), the global final energy demand continues to grow by $50 \%$ in the period to 2060 , with cumulative energy sector $\mathrm{CO}_{2}$ emissions increasing by over $1750 \mathrm{Gt}$. Although the RTS does not offer complete conditions to achieve global climate objectives, it is conservative and still represents a significant shift from a historical "business as usual" approach. According to RTS, CCS will represent about a contribution to the emissions reduction about $14 \%$ by 2060 (IEA 2017). In 2018, EOR method was responsible for about $88.0 \%$ of the global $\mathrm{CO}_{2}$ geologically stored according to CCS strategy in the world (GCCSI 2018). By 2060, $2.3 \mathrm{Gt}$ of $\mathrm{CO}_{2}$ must be stored each year. It means a CCS deployment rate of more than double to that of the growth of the oil industry during the last century. By 2050, only Carbon capture utilization and storage (CCUS) will be responsible by $9.0 \%$ of the emissions reduction (GCCSI 2019).

$\mathrm{CO}_{2}$-EOR offers a significant reward: extraction up to 375 billion barrels of additional oil from suitable fields and geological storage up to $360 \mathrm{Gt} \mathrm{CO}_{2}$ in the process for the next 50 years, globally (IEA 2015). In contrast with other dedicated geological storage methods, such as, $\mathrm{CO}_{2}$ storage within saline aquifers-passive geosequestration method, $\mathrm{CO}_{2}$-EOR produces supplementary wealth throughout the

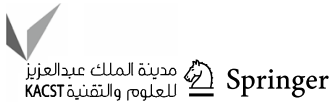


extraction of billion barrels of additional oil. It is a result of current short- and long-term projections for the global energy demand, which exhibits the fossil fuel dominance in general and the oil in particular and considers their effects on the GHG concentrations in the atmosphere. In this scenery, $\mathrm{CO}_{2}$-EOR establishes a direct connection between the petroleum energy system and CCS, by which oil industry assumes a new and positive role to the climate change mitigation.

\section{Highlights on the origin of the carbonate reservoirs of Pre-salt}

The geological structures in the Pre-salt Province have tectonic origin along the super-continent Gondwana break up, approximately 160 million years ago. This significant geological movement also resulted in separating the South American and African continents and formation of South Atlantic, by Early Cretaceous. According to the geological explanation model of this event, a differential rotation about a migrating pole positioned in northeastern Brazil rotated clockwise relative to Africa and separated these two continents (Szatmari 2000). The large lithospheric mass and its immense gravitational energy generated an enormous compressive angular momentum in northeast Brazil driving this break up phenomenon. Consequently, a large rifting process was initiated, irradiating the occurrence of significant faults and folds among others geotectonic movements. These vast geological effects induced the emergence of grabens and hosters, which were essential as the locus for future sediments filling and formation of the sedimentary basins.

In this process, outstanding structures were opened in the entire Brazilian continental margin, with faults step downward to the ocean and large vertical displacements, ranging up to thousand meters, to where there are today as uplifted faults block separating the depositional sites, such as the Vitoria, Cabo Frio and Florianopolis lineaments (Highs). These formed structures are transverse with respect to the Brazilian margin and composed of east-west belts. For this study, they have a particular geological relevance because they delimit the Campos and Santos basins located inside the Pre-salt Province.

The crustal distension and necking during the rift stage provoked the break out of a relatively narrow and elongated gulf separating the South American and African continents floored by a continental-transitional type of crust. At this site, there were irregular tectonic activities involving various uplifted and subsidized areas with large structures, including the Rio Grande and Walvis ridges; these features, during the continental drift phase, moved forward to western Africa (Asmus and Baisch 1983).

Going beyond the morphological barriers located at the physiography of the proto-oceanic crust in Early Cretaceous, and at deeper sites of the basins (their higher subsidence), the marine water was confined, forming an extensive habitat of saline lakes. These physical conditions created a territory of low energy and appropriate salinity, stimulating a suitable environment for thriving bacteria colonies, organosedimentary deposits, which had accreted because of the benthic microbial community trapping and binding to detrital sediments forming the locus for mineral precipitation, i.e., the microbialities. The main internal framework of these microbialities is the formation of biosedimentary calcareous constructions in the lithified domical and laminated forms, the stromatolite structure.

These physical conditions were found together with high temperatures during Aptian, with a severe climate environment, when the average temperature was significantly higher than the recent and current periods. The previously referred habitat of saline lakes submitted to these climate surroundings and caused a high precipitation of salts, giving origin, during Aptian, to a thick evaporitic layer. The simultaneous engagement of these phenomena allowed the break out of a deep and wide evaporitic layer at the eastern Brazilian and western African margins (Asmus and Baisch 1983; Freitas 2006).

At the Brazilian margin, these evaporities can reach (2000-2500) $\mathrm{m}$ thickness and a width of up to $400 \mathrm{~km}$ at the Santos basin, deposited in the geologic period of (500-600) $\mathrm{ka}$. In the direction from southern to northern, the evaporites suffer narrowing and reach no more than a $100 \mathrm{~km}$ width at the Sergipe-Alagoas basin (Freitas 2006; Szatmari 2000).

Because of the previously mentioned geotectonic effects at the Eastern Brazilian margin, subsequently, a thermal contraction event caused the collapse and subsidence of the crustal domes, and these features generated slight sags in the crust. The filling of these sag basins by carbonates and clastic sediments formed the giant pools in the Pre-salt Province, which are known today. Accordingly, Pre-salt contains microbial and stromatolitic reservoirs, being extremely sagging reservoirs (Carminatti et al 2009).

Pre-salt province is under deep and ultra-deep waters at approximately (1500-3000) $\mathrm{m}$ depth, under which there is an extensive and thick autochthonous evaporites bed (2000-2500) m. In Pre-salt, the hydrocarbons migrated throughout and within the reservoirs, having the evaporites as a high-quality seal. Above this salt coverage, from the Albian to Recent, a fine sedimentary marine layer was deposited on the top of the evaporites, conforming an overlay about (1000-1500) $\mathrm{m}$, that is, a Post-salt marine sediments to the sea floor. Nowadays, the main reservoirs of Pre-salt are being explored at an average water depth and evaporite thick, respectively, of $2200 \mathrm{~m}$ and $2000 \mathrm{~m}$. Thus, these reservoirs are reached to the depth up to (5500-6500) $\mathrm{m}$ true vertical depth subsea (TVDSS) and approximately (200-300) km offshore. Submitted to 
these severe conditions, presently, Pre-salt represents the most challenging of offshore petroleum energy system in the world (Barbassa 2007; Carminatti et al 2009; Riccomini et al 2012).

Its reservoirs extend through long and wide offshore coastal area of $800 \mathrm{~km}$ length and $200 \mathrm{~km}$ width, including five states, Espírito Santo, Rio de Janeiro, São Paulo, Paraná, and Santa Catarina. At the above depth and between the Vitoria and Florianopolis Highs and the passing through Cabo Frio (Rio de Janeiro) High, Pre-salt Province measures $149,000 \mathrm{~km}^{2}$ as mentioned previously (Fig. 1).

This figure indicates the main physiographies of the Province: the effective geological structure of the Pre-salt Province (Polygon) with its reservoirs is shown in purple, within the Campos and Santos basins as above depicted. Its north and south limits, respectively, are defined by the Vitoria and Florianopolis Highs and cross through Cabo Frio High, which are represented as gray dashed lines. A hinge line in blue, at the west Polygon, occurs along the entire Brazilian margin. This figure again demonstrates by the furthest line at the east from the continent, in red, the east boundary of the evaporites layer.

\section{Reservoir and fluids characteristics of Pre-salt and their adequacy to $\mathrm{CO}_{2}$-EOR}

Pre-salt contains a giant amount of hydrocarbons in microbial carbonate reservoirs developed in high salinity lake environment and sealed by thick (kilometric) evaporite layer as aforementioned. According to its tectonic origin, initially, the Province received terrestrial and lacustrine sediments with a section of Coquinas containing a high intergranular and vugular porosity, also exhibiting fractures. Along its geological development microbial sequences were deposited in the rift and sag sections. The microbial sequences were deposited in the sag and are mostly constituted by stromatolites, grainstones and laminates. At the Santos Basin, the main Pre-salt reservoirs are microbial carbonates with stromatolite framework, presenting dense level of heterogeneities and vast vertical to horizontal permeability anisotropy (Pizarro and Branco 2012; Salomão et al 2015).

The hydrocarbons found in the Province present a variation between fields, but most comprises oil around $30^{\circ}$ API (it also can be ${ }^{\circ} \mathrm{API}>28$ ), viscosity approximately $1.0 \mathrm{cp}$ and gas oil ratio (GOR) ranging (200-400) $\mathrm{Sm}^{3} /$ $\mathrm{Sm}^{3}$. According to the reservoir and fluids characterization, there is another important concern on the high level of $\mathrm{CO}_{2}$

Fig. 1 Pre-salt Province, Brazil

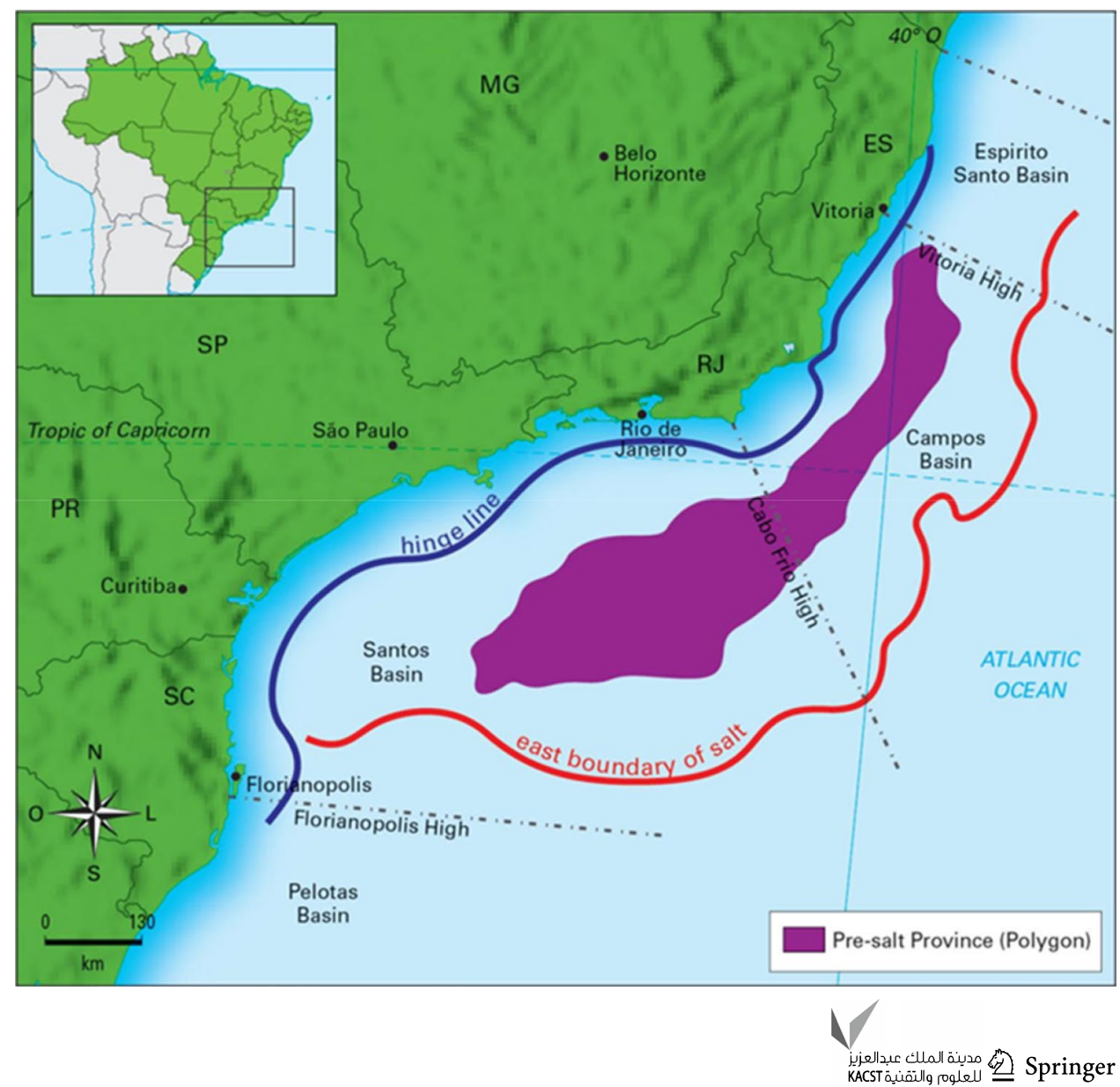


contamination in this level of solution gas, which varies from (8-15)\%, presenting high corrosion potential of the pipeline systems due to its reaction with water (produced and injected) and formation of carbonic acid $\left(\mathrm{H}_{2} \mathrm{CO}_{3}\right)$. This acid also produces $\mathrm{pH}$ reduction in the environment, including the water $\mathrm{pH}$, having as consequence formation of $\mathrm{H}_{2} \mathrm{~S}$, and the presence of this compound provokes both effects of localized corrosion and material failures as result from the sulfide stress corrosion (SSC). These corrosion issues are being tackled by using of special corrosion resistant alloys, protective plastic coatings in the piping systems together with a continuous downhole chemical injection for corrosion inhibition (Beltrão et al. 2009).

The complexness of Pre-salt requires from the interested players in its exploration robust strategy. The current operators have recommended supporting this strategy on three pillars: First, and extensive data acquisition gathered rock and fluids characterization, considering their static and dynamic parameters in pore scale and in well and field scale with focus on the characteristics what have direct influence on the displacement and recovery of the fluids. This data system must include field parameters regarding lift correlations, potential formation damage mechanisms and flow assurance issues, involving, for example, appraisal wells, sidewall cores, rock coring, well tests (DST), well logs, EWT, among others. The second pillar regards to full interpretation and multidisciplinary workflow, including three main topics: (1) parameters responsible for determining the volume of hydrocarbon in place; (2) characteristics what identify and control the displacement in the porous media; (3) the adopted strategy and mechanisms for fluid recovery. Finally, the third pillar is to develop and apply a robust development plan, involving, first, an flexible strategy which consider the high degree of uncertainties by the large dimensions of Presalt fields and by the complex rock-fluid interaction and system. It also is fundamental to think about multiple scenarios for both static and dynamic properties and build a recovery strategy with possibility to be profitable in different situations (Salomão et al. 2015).

Since initial studies and exploration activities of Pre-salt Province (Pre-salt Cluster) were thought about $\mathrm{CO}_{2}$-EOR with WAG. This previous thinking derives from the following driving factors:

- relative high GOR combined with large $\mathrm{CO}_{2}$ contamination;

- prevention to $\mathrm{CO}_{2}$ emissions to the atmosphere, needing, then, to reinject $\mathrm{CO}_{2}$ stream within the reservoir;

- water injection as a natural alternative for using as result of technical and economic argumentation;

- presence of light and low viscosity oil;

- first test results showing preliminarily relative high residual oil saturation;
- reservoir simulation indicated that EOR operations could result substantial RF increasing;

- security for $\mathrm{CO}_{2}$ geosequestration due to the existing rock and the supplementary seal from thick evaporite layer, which spreads on the cluster.

Facing these drivers, a screening study also was developed about several EOR methods, considering the geology and reservoir characterization and ultra-deep waters conditions. $\mathrm{CO}_{2}$ is multiple contact miscibility with crude oil and extracts light-to-intermediate components from the oil. Miscibility also depends too from minimum miscibility pressure (MMP) to be reached and/or exceeds it. The density and, as consequence, the solubility of $\mathrm{CO}_{2}$ in oil decrease with temperature, so the MMP required for a given oil will increase as well as temperature increases. If the temperature increases with depth, the same occurs with MMP, but, luckily, the fracture pressure of reservoirs increases much faster than temperature with depth, what signify that there is a secure MMP "window of opportunity" for reaching miscibility. Normally, it is adopted a safety margin of approximately $152 \mathrm{~m}$ above typical reservoir fracture depth for the required MMP pressures (Taber et al. 1996). Using a specific condition of reservoir and adopting the same screening to achieve the MMP, the depth must also be minimum of $750 \mathrm{~m}$, that is, $h \geq 750 \mathrm{~m}$. After this vertical quota within the rock, the miscibility will favorably be triggered off (Maroto-Valer 2010). It is essential to clarify that all these data represent referential figures, because as every geology of reservoir and fluids characteristics are developed by means of non-equilibrium thermodynamics in the course of geologic time, for each one there are specific conditions, measures and analyses to be made.

When data of the geology and fluid characterizations of Pre-salt had exhibited to the $\mathrm{CO}_{2}$-EOR in carbonate reservoir as above exposed, it was verified their adequacy for this method. According to this evidence, a pilot test was planned and implemented as described as follows.

\section{Pilot test in Pre-salt: $\mathrm{CO}_{2}$-EOR with WAG}

Normally, offshore EOR projects require higher (than onshore) constraints and capital expenditure, implying additional technical and economic risks. Due to the logistic limitations and great difficulties to install plants for chemical fluids injection, the cited screening clarified that chemicals EOR were considered unfeasible. In front of so intricacy, with Pre-salt immersed in ultra-deep waters and underneath of thick evaporite layer, with purpose to provide valuable information and to optimize design for future production system and EOR strategies, have been developed a pilot test in Lula field (formerly known as Tupi), the Lula Pilot. 
When implemented an appraisal plan including drilling of additional wells, with several DSTs and high-resolution seismic shot, Lula field revealed, in terms of petro-physical characteristics (as well microbial carbonate Pre-salt Province in general), good adequacy to $\mathrm{CO}_{2}$ injection with WAG (Pizarro and Branco 2012; GéoVal et al. 2014).

Lula field is at Pre-salt, region of Santos Basin, in $2000 \mathrm{~m}$ water depth, a thick salt column about $2000 \mathrm{~m}$ and approximately $300 \mathrm{~km}$ from the coast. Its oil density grades between $\left(28 \leq^{\circ} \mathrm{API} \leq 30\right)$ and GOR $(200-300) \mathrm{Sm}^{3} / \mathrm{Sm}^{3}$. Its level of $\mathrm{CO}_{2}$ content in solution gas varies from $(8-15) \%$.

The strategy of test in Lula field used techniques of dynamic information such as extended well tests (EWT) (to accomplish long-term production profile of the wells), production pilots (to appraisal performance of recovery methods), reservoir coring, complete logging, high-resolution seismic techniques and interpretation, evaluation of different well geometries, fluid sampling and laboratory tests, flow assurance analysis and so on. This strategy had been applied in the sense to reduce risks, optimize production systems, allow tradeoffs between costs and revenues and create a previous knowledge for building definitive systems aiming large-scale operations. Thus, two EWT in Lula, one at the South and another at Northeast of its global area, in May 2009 and April 2011, respectively. They had presented similar oil extraction level of approximately 2385 cubic meter per day $\left(2385 \mathrm{~m}^{3} / \mathrm{d}\right)$. Lula pilot began its operation in October 2010, but was also considered as EWT; and in April, 2011, the gas injection had started with an specific well (Pizarro and Branco 2012).

The drives and classical basis for $\mathrm{CO}_{2}$-EOR with miscibility and the screening aforementioned demonstrate conditions such as adequacy of thermodynamic potential present in the reservoirs of Pre-salt in general for this method, the WAG process efficiency in continuous reservoirs without steep inclination, oil presenting high swelling and reduced viscosity in the presence of the injected gas and so forth. These authors describe that comparing these classical principles with the Lula scenario was decided to test EOR methods with $\mathrm{CO}_{2}$ and hydrocarbon gases to be injected within this field and laboratory experiences and analyses were planned to be made. According to the low concentration of $\mathrm{CO}_{2}$, was selected to use WAG- $\mathrm{CO}_{2}$ with reinjection of all produced gas $\left(\mathrm{HC}\right.$ plus $\mathrm{CO}_{2}$ ) along the whole reservoir extent. Among other attributes, the Lula geomodel gave emphasis on the correlation of seismic characteristics to porosity and saturation data with purpose to identify "optimal/ideal places" and the main internal heterogeneities. In their study, those authors reported that this analysis was supported by the dynamical data gathered from the EWTs and the drilling of strategically located reservoir data acquisition wells.

In the sequence of this EOR strategy and searching to understand and represent the phase behavior of fluids in Lula field, were adopted compositional simulation considering both opportunities as above depicted, considering waterflooding and WAG with hydrocarbon gases (HC) and/or $\mathrm{CO}_{2}$. Laboratory experiments also were made for conventional PVT curves, determination of viscosity and swelling of oil and, by the slim tube technique, MMP was appraised. The produced data provided the adequate equation of state (EoS), and its parameters were developed. Engineering actions on the well number and spacing and injection patterns and control were also made. As Lula field presents relatively low reservoir temperature $(60-70){ }^{\circ} \mathrm{C}$ (an average for Pre-salt), reduced viscosity and high pressures, than, it represents a large promise to reach the MMP (and miscibility). In this pilot test, were practiced two WAG injectors and one gas injector. This feature also was able to flexible either water or gas in the injection wells and capability to alternate gas injection through different wells, which had great importance to ratification expectative on the additional oil recovery by this method. It also is described that some well specific techniques were tried to optimize the RF by fluid injection in carbonates, such as, acid stimulation, drilling of highly deviated and horizontal wells and placement of injectors in lower permeability sites of reservoir (Pizarro and Branco 2012).

Although the benefits of gas injection for this test of oil recovery, some concerns on negative events had been considered, regarding to, for example, as non-polar solvent, $\mathrm{CO}_{2}$ and $\mathrm{HC}$ gas can provoke flocculation of colloidal heavy asphaltene components from the oil. Reduction in the pressure on the oil flow rates within the risers can also makes the gas to come out of solution, lowering the flow temperature, creating conditions to wax deposition. Additionally, there are two significant issues regarding to $\mathrm{CO}_{2}$ injection in carbonate rocks and its potential formation of calcium carbonate scale and corrosion in the well casing and tubing by the carbonic acid as a result of the reaction of $\mathrm{CO}_{2}$ with de injected and produced water. The authors reported that flow assurance and integrity issues with their effects were investigated via reservoir simulation studies which are inside the technological programs of Petróleo Brasileiro S. A. (Petrobras) to Pre-salt, together with special design of flexible flow lines and risers to deal with $\mathrm{CO}_{2}$. Whereas special alloys and plastic covered pipes and continuous downhole chemical injection deal with corrosion of the well system. Inside the strategy for Lula Pilot, the authors reported that were planned as favorable to confirm the RF increasing by the EOR application in the field, the following elements:

- use of intelligent completation to mitigate the risk of preferential flow and early breakthrough of injected fluids in the reservoir;

- flexibility to inject either water or gas in the injection wells;

- possibility to alternate the gas injection through different wells. 
Among other initiatives, the studies recommended Lula Pilot for $\mathrm{HC}$ by WAG (WAG-HC) and $\mathrm{CO}_{2}\left(\mathrm{WAG}-\mathrm{CO}_{2}\right)$ and WAG by a mix of $\left(\mathrm{HC}-\mathrm{CO}_{2}\right)$. Thus, in April 2011, the injection well started its operation with a rate of 1.0 million $\mathrm{m}^{3} / \mathrm{d}, \mathrm{HC}$ as main share with some $\mathrm{CO}_{2}$ content; from September 2011 on, with $\mathrm{CO}_{2}$ separation from the produced gas, the injection conditions were changed, mainly composed by $\mathrm{CO}_{2}$ with concentration higher than $80 \%$ and rate of $350,000 \mathrm{~m}^{3} / \mathrm{d}$. The injection process was controlled by monitoring pressure gauges and use of tracer.

Under these parameters, in April 2011 a production well presented an oscillating flow rate of about (2000-3000) $\mathrm{m}^{3} / \mathrm{d}$ of oil, in December of that year, another well presented a flow rate of approximately $11,000 \mathrm{~m}^{3} / \mathrm{d}$. In the end of this month 2011, the cumulative injection and extraction were, respectively, 177.3 million $\mathrm{m}^{3}$ of gas and 3.1 million $\mathrm{m}^{3}$ of oil and 845.8 million $\mathrm{m}^{3}$ of natural gas. See resume in Table 1.

Lula pilot was essential to calibrate and select the best strategy for miscible EOR, $\mathrm{CO}_{2}$ and/or $\mathrm{HC}$ by WAG and for RF increasing (additional oil barrels) and profitability of projects. It also provided the basis to adopt the best way for field developments not only at its own area as well as for Pre-salt blocks in the Santos Basin (Pizarro and Branco 2012).

This evaluation on the amount of the injected $\mathrm{CO}_{2}$ inside the reservoir was also considered as promising for continuous use through the Province. Therefore, in Presalt, the recycling of the released $\mathrm{CO}_{2}$ by the oil pools, reinjection within the reservoir for gas geosequestration, and RF increasing also represent an advanced practice constituting significant benefits for the environmental issue, economic results and for the CCS strategy.

\section{Potential of $\mathrm{CO}_{2}$-EOR at the Pre-salt: additional oil recovering and $\mathrm{CO}_{2}$ geosequestration}

The most important new discovered reserves in Brazil country and the world are found in the Pre-salt Province, with an extension of $149,000 \mathrm{~km}^{2}$ of the Brazilian continental shelf,

Table 1 Lula pilot-cumulative injection and extraction (up to December 31, 2011)

\begin{tabular}{llll}
\hline Gas injected $\left(\mathrm{Mm}^{3}\right)^{*}$ & \multicolumn{3}{l}{ Extracted/produced $\left(\mathrm{Mm}^{3}\right)^{*}$} \\
\cline { 2 - 4 } & Oil & Gas & Water \\
\hline 177.3 & 3.1 & 845.8 & 0.0 \\
\hline
\end{tabular}

Based on Pizarro and Branco (2012)

Specifically for Lula pilot

*Million $\mathrm{m}^{3}$ involving five States. The massive dimensions of oil extraction at the province expose that only Tupi pool in it, with an appraisal area if approximately $2000 \mathrm{~km}^{2}$, has the reserves amounting to nearly (5.0-8.0) billion barrels for recovering (Formigli et al 2009; Fraga et al. 2015). At the Libra pool, another example, the expected recovery is approximately (8.0-12) billion barrels and 1.4 million barrels per day (1.4 Mbpd) during its top extraction period (Shell 2016). For understanding the importance of Pre-salt, consider the fact that Petrobras took 45 years since its foundation to achieve 1.0 Mbpd (1998) with thousands of wells, whereas it needed only 10 years (middle 2016) after discovery of Pre-salt and 52 wells, for achieving the same daily extraction level. Currently, Pre-salt contributes with 2739 Mboe/d and represents $70.3 \%$ of the total Brazilian extraction of oil equivalent. Nowadays, Lula field has an accumulated extraction of 2000 Mboe and it is the largest extractor/producer field in Brazil, with an oil/gas average extraction, respectively, of 988,000 barrels/43.2 $\mathrm{Mm}^{3}$ per day (ANP 2020). According to this reference, accounting separated oil and gas, Brazil, in 2020, is extracting an average of 3.078 million barrels per day (3.078 Mbd) of oil and $130 \mathrm{Mm}^{3} / \mathrm{d}$ of natural gas.

Since 2016, when accomplished about 1.0 Mbpd to now, Pre-salt extraction of oil has been growing and reaches $2.179 \mathrm{Mbpd}$, of oil, specifically, in 2020, that is, in the period (2016-2020/August), Pre-salt extraction growth was higher than $100 \%$. In this period, the annual average extraction of Pre-salt has been growing about $19.0 \%$. Considering the same month and period of last year (2019-2020), the total Brazilian extraction of oil grows 10.9\%, whereas Pre-salt grows 25.4\% (ANP 2017, 2020). This large result is the growth expectation to the next years, mainly due to the systematic entry by recent years of new global oil Companies to explore the Province.

It is necessary to clarify that Law \#13,365 on 29 November 2016 changes the former Law \#12,351 on 22 December 2010 , eliminating the total authority for exploring by the Brazilian State Company and opened Pre-salt to private and international oil Companies in general. All of new Brazilian regulation for the sector follows this new law. The foreign interested to explore Pre-salt needs to know it (Brazil 2016). The new global Companies nowadays present in Pre-salt, as above depicted, result from this law.

In 2020, total Brazilian average extraction is 3.078 Mbpd and Pre-salt alone 2.179 Mbpd as above depicted. In 2030, Brazil will extract an average about 4.3 Mbpd and $5.2 \mathrm{Mbpd}$ in 2040, accounting a compound average annual growth rate about $2.8 \%$ (IEA 2018).

Considering a very conservative average annual growth rate about $6.0 \%$ for the oil extraction of Pre-salt and the middle point in time (2020-2040), that is, 2030 as a median for this period, it is possible to reach the final growth around $79.0 \%$ along these 10 (ten) years (2020-2030). This growth 
achieves oil extraction of Pre-salt about 3.9 Mbpd, which represents approximately $90 \%$ of the $4.3 \mathrm{Mbpd}$ above cited.

According to these indicators, this investigation assumes the median data as a yearly average regarding to the total 20 years period (2020-2040), that is, a total extraction about 4.3 Mbpd and the share of Pre-salt on this total will be stabilized in these $90 \%$, that is, $3.9 \mathrm{Mbpd}$. Thus, in this assumed forecast, Pre-salt extraction will be permanent as yearly average to the considered complete period. In these assumed conditions, Pre-salt will extract approximately 1423 million barrels per annum (1423 Mbpa) along the period, which (adopting US oil barrel) represents $226.0 \mathrm{Mm}^{3}$ of oil. Facing the data aforementioned and assuming a moderate average level of GOR of approximately $300 \mathrm{Sm}^{3} / \mathrm{Sm}^{3}$ with a $10 \% \mathrm{CO}_{2}$ contamination, the $\mathrm{CO}_{2}$ emissions will be approximately 6.78 billion $\mathrm{m}^{3}$ per annum, which is equivalent to $13.3 \mathrm{Mt} \mathrm{CO}_{2}$ emissions per annum. As a yearly average during the complete period, thus Pre-salt will release approximately $266 \mathrm{Mt} \mathrm{CO}_{2}$, which represents its potential of $\mathrm{CO}_{2}$ reinjection inside the respective reservoirs for the next 20 years (2020-2040). $\mathrm{CO}_{2}$ can be the most expensive operational cost of any $\mathrm{CO}_{2}$-EOR facility, mainly at OCDE countries. This high cost of $\mathrm{CO}_{2}$ means the gas must be monitored at the surface and within the reservoir to ensure its optimal use. Ultimately, all the $\mathrm{CO}_{2}$ injected into an oil field for EOR remains trapped in the pore space that originally held the oil and other fluids (GCCSI 2019). Thus, the potential here mentioned for Pre-salt means a real storage.

Conventional secondary recovery techniques extend the productive life of a field by injecting water or gas to displace the oil and drive it to the production wellbore, resulting in the recovery of $20-40 \%$ of the original oil in place. Using EOR techniques (special secondary recovery techniques), the final extraction can reach up to $60 \%$ or more of this original oil of the reservoir (DOE 2020). In consonance with this assumption and using this positive difference of $20 \%$ and adopting $\mathrm{CO}_{2}$-EOR, Pre-salt presents the potential to extract about 5.7 billion of additional oil barrels in the next 20 years.

Nowadays, Petrobras reinjects about 3.0 $\mathrm{Mt} \mathrm{CO}_{2}$ per annum (3.0 Mtpa of $\mathrm{CO}_{2}$ ) in the Pre-salt Santos Basin. It reached a milestone of $10 \mathrm{MtCO}_{2}$ and is continually expanding the capacity of its floating production storage and offloading (FPSO) units, aiming to cumulatively reinject more than $40 \mathrm{Mt} \mathrm{CO}_{2}$ by 2025 (GCCSI 2019).

Due to issues such as: nature of reservoir rocks, high GOR and $\mathrm{CO}_{2}$ content, corrosion of the subsystems involved, environmental protection, high pressures and low temperatures of the reservoirs, among others, after pilot test and the large current extraction of Lula field above depicted, miscible $\mathrm{CO}_{2}$-EOR systematically progresses in the Province together with its exploration and knowledge. In front of these characteristics and considering the availability of very good sealing rock by the thick salt layer on the reservoirs, which offer high security for the $\mathrm{CO}_{2}$ geosequestration, this practice already began and it is demonstrating to be feasible and beneficial.

\section{Summary and conclusions}

This study analyzes about the energy as the main anthropogenic forcing of climate change, resulting from the intense and global use of the fossil fuels, which currently reach $81.3 \%$ of the total primary energy supply in the world. Inside this worldwide energy matrix, oil has the higher share of $31.6 \%$ and will continue predominant by long term. Oil also is the second most important GHG emitter (immediately after coal), with $34.1 \%$ of the total world $\mathrm{CO}_{2}$ emission by fuel. Afterward, this research analyzes the global policy of $\mathrm{CCS}$ and its direct connection with $\mathrm{CO}_{2}$-EOR and by means of this method the new role of the petroleum energy system to the climate change mitigation. Due to $\mathrm{CO}_{2}$-EOR includes broad benefits because produces vast $\mathrm{CO}_{2}$ emissions reduction to the atmosphere and large amount of additional barrels of oil, it is the most important $\mathrm{CO}_{2}$ geosequestration method, reaching, in 2018, about $88 \%$ of the total carbon geologically stored in the world. CCS will contribute to the worldwide emissions reduction about $14 \%$ by 2060 and only CCUS will contribute to this target with about $9.0 \%$ by 2050 .

Thus, this investigation studies the Pre-salt Province in Brazil as the biggest set of giant oil fields recently discovered in the world with its estimation of extraction volumes of billions barrels of oil. Nowadays, it is responsible for about $70.3 \%$ of the total Brazilian oil extraction, representing $2.739 \mathrm{Mboe} / \mathrm{d}$. The national regulation for the oil and gas sector is changed (Law \#13,365 on 29 November 2016 changes the former Law \#12,351 on 22 December 2010) in Brazil to enter international Companies for exploring Presalt, which already present good producing results.

This study also presents its tectonic origin evolving since super-continent Gondwana break up, approximately 160 million years ago and its complex set of microbial carbonate reservoirs with stromatolite framework located in ultra-deep waters and underneath of thick salt layer (2000-2500) m. Its reservoirs can be reached to the depth up to (5500-6500) m TVDSS and approximately (200-300) km offshore. The fluids of Pre-salt comprises oil with ${ }^{\circ} \mathrm{API} \approx 30$, viscosity approximately $1.0 \mathrm{cp}$ and GOR ranging (200-400) Sm3/Sm3, with a high $\mathrm{CO}_{2}$ contamination about (8-15)\%.

Due to its high GOR combined with large $\mathrm{CO}_{2}$ contamination, prevention to $\mathrm{CO}_{2}$ emissions to the atmosphere, and need to reinject the gas stream within the reservoir, presence of light and low viscosity oil and test results showing preliminarily relative high residual oil saturation,

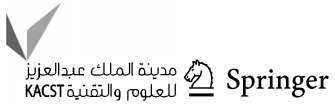


among others, pilot test was made for understanding the opportunity of the $\mathrm{CO}_{2}$-EOR at Province. Reservoir simulation also indicated that EOR operations could result substantial RF increasing.

The pilot tests are described inside this paper and corroborated adequacy of the miscible $\mathrm{CO}_{2}$-EOR with WAG in Pre-salt. It also demonstrated that this method is feasible and beneficial at Pre-salt. It induced for the future of the exploration large use of this EOR method also considering $\mathrm{CO}_{2}$ geosequestration. The supplementary seal from thick evaporite layer, which spreads on the cluster, also presents broad security for $\mathrm{CO}_{2}$ geological storage.

As solid substances, nanoparticles can withstand $\mathrm{CO}_{2}$ flooding, mainly to those harsh environment and hightemperature reservoirs in which surfactant-stabilized $\mathrm{CO}_{2}$ foam cannot survive, providing a novel means for improving mobility control agents for $\mathrm{CO}_{2}$-EOR and promising $\mathrm{RF}$ increasing. Although this potential successful of these nanoparticle applications in the field, Pre-salt is formed by harsh environment, including high pressure, but low temperature reservoirs. Before its geographic location with large distance from the shore, their difficulties in logistics and additional technical and economic risks and great adversities to install plants for chemical fluids injection, Pre-salt presents hard limitations to the use of these solid substances together with chemical compounds.

$\mathrm{CO}_{2}$-EOR offers a fertile consequence to CCS: extraction of up to 375 billion barrels of additional oil and up to $360 \mathrm{Gt} \mathrm{CO}_{2}$ to be geological stored inside the oil reservoirs in the next 50 years, globally. This study concludes that Pre-salt exhibits potential to contribute with 5.7 billion of additional oil barrels and $266 \mathrm{Mt} \mathrm{CO}_{2}$ to be geological stored for the next 20 years. Nowadays, there is an injection about 3.0 Mtpa of $\mathrm{CO}_{2}$ in Pre-salt Santos Basin and Petrobras already reaches the milestone of $10 \mathrm{Mt} \mathrm{CO}_{2}$ in offshore Brazil.

$\mathrm{CO}_{2}$-EOR connects the petroleum energy system to CCS and transforms its reservoirs in a carbon sink, representing a substantial role in the energy efficiency of energy resources recovering from the biosphere and a high contribution to the climate change mitigation.

Due to its huge complexity, Pre-salt requires robust strategy for exploring, contemplating vast geophysical data and analysis and flexible planning with multiple exploration scenarios.

Funding There is no funding supply or obligations to this work.

Open Access This article is licensed under a Creative Commons Attribution 4.0 International License, which permits use, sharing, adaptation, distribution and reproduction in any medium or format, as long as you give appropriate credit to the original author(s) and the source, provide a link to the Creative Commons licence, and indicate if changes were made. The images or other third party material in this article are included in the article's Creative Commons licence, unless indicated otherwise in a credit line to the material. If material is not included in the article's Creative Commons licence and your intended use is not permitted by statutory regulation or exceeds the permitted use, you will need to obtain permission directly from the copyright holder. To view a copy of this licence, visit http://creativecommons.org/licenses/by/4.0/.

\section{References}

Agência Nacional do Petróleo, Gás Natural e Biocombustíveis (ANP) (2017) Produção de petróleo no Pré-sal ultrapassa pela primeira vez a do Pós-sal. ANP, Rio de Janeiro. ANP Publishing. http:// www.anp.gov.br/noticias/anp-e-p/3912-producao-pre-sal-31jul 2017. Accessed 10 June 2020

Agência Nacional do Petróleo, Gás Natural e Biocombustíveis (ANP) (2020) Boletim da Produção de Petróleo e Gás Natural. ANP, Rio de Janeiro. ANP, August, 2020, Nr. 119, p 2

Asmus HE, Baisch PR (1983) Geological evolution of the Brazilian continental margin. Episodes 4:3-9

Barbassa AG (2007) Fato relevante: Análise da área de Tupi. Petrobras Publishing, Petrobras, Rio de Janeiro. http://siteempres as.bovespa.com.br/consbov/ArquivosExibe.asp?site=\&proto colo=140478. Accessed 19 August 2020

Beltrão RLC, Sombra CL, Lage ACVM, Fagundes Netto JR, Henriques CCD (2009) Challenges and new technologies for the development of the Pre-salt Cluster, Santos Basin, Brazil. In: Offshore technology conference (OTC), 4-7 May 2009. OTC, Houston, Paper OTC 19880

Blunt MJ, Fayers FJ, Orr FM Jr (1993) Carbon dioxide in enhanced oil recovery. Energy Convers Manag 334:1197-1204

Brazil (2016) Lei No 13.365, de 29 de novembro de 2016. Altera a Lei no 12.351 , de 22 de dezembro de 2010, para facultar à Petrobras o direito de preferência para atuar como operador e possuir participação mínima de $30 \%$ (trinta por cento) nos consórcios formados para exploração de blocos licitados no regime de partilha de produção. Brazilian Parliament and Government, Brasilia DF

Carminatti M, Dias JL, Wolff B (2009) From turbidites to carbonates: breaking paradigms in deep waters. In: Offshore technology conference (OTC), 4-7 May 2009. OTC, Houston, Paper OTC 20124

de Freitas JTR (2006) Ciclos deposicionais evaporíticos da bacia de Santos: uma análise cicloestratigráfica a partir de dados de dois poços e de traços de sísmica. MSc Dissertation, Federal University of Rio Grande do Sul

Dejam M, Hassanzadeh H (2018a) Diffusive leakage of brine from aquifers during $\mathrm{CO}_{2}$ geological storage. Adv Water Resour $111: 36-57$

Dejam M, Hassanzadeh H (2018b) The role of natural fractures of finite double-porosity aquifers on diffusive leakage of brine during geological storage of $\mathrm{CO}_{2}$. Int J Greenh Gas Control 78:177-197

Formigli JM, Pinto ACC, Almeida AS (2009) Santos Basin's Pre-Salt reservoirs development: the way ahead. In: Offshore technology conference (OTC), 4-7 May 2009. OTC, Houston, Paper OTC 19953

Fraga CTC, Pinto ACC, Branco CCM, Pizarro JOS, Paulo CAS (2015) Brazilian Pre-Salt: an impressive journey from plans and challenges to concrete results. In: Offshore technology conference (OTC), 4-7 May 2015. OTC, Houston, Paper OTC-25710-MS

GéoVal BH, Terrazas RR, Henrique S (2014) $\mathrm{CO}_{2}$ from Southeast Asia to Brazil: making your enemy your ally? In: Offshore technology conference (OTC), 25-28 March 2014. OTC, Kuala Lumpur, Paper OTC-25048-MS 
Global CCS Institute (GCCSI) (2018) The global status of CCS. GCCSI, Canberra, pp 17-20

Global CCS Institute (GCCSI) (2019) Global status of CCS. GCCSI, Canberra, pp 18-22

Godoi JMA (2015) A contribution of the petroleum energy system to climate change mitigation: enhanced oil recovery with geological $\mathrm{CO}_{2}$ storage in the reservoir. Ph.D. Dissertation, University of São Paulo

Goldemberg J, Lucon O (2008) Energia, meio ambiente e desenvolvimento. University of São Paulo Press, São Paulo, pp 169-210

Intergovernmental Panel on Climate Chante (IPCC) (2014) Climate change 2014: mitigation of climate change. Working group III contribution to the fifth assessment report of the intergovernmental panel on climate change. IPCC, New York, pp 6-9

International Energy Agency (IEA) (2015) Storing $\mathrm{CO}_{2}$ through enhanced oil recovery 2015. IEA, Paris, pp 25-26, 39

International Energy Agency (IEA) (2017) Energy technology perspectives 2017. IEA, Paris, pp 19-39

International Energy Agency (IEA) (2018) World energy outlook 2018. IEA, Paris, pp 37-39, 136-140, 144-146

International Energy Agency (IEA) (2020) Key world energy statistics 2020. IEA, Paris, pp 6, 12, 54

Kovscek AR, Cakici MD (2005) Geological storage of carbon dioxide and enhanced oil recovery II: cooptimization of storage and recovery. Energy Convers Manag 46:1941-1956

Lake LW (2010) Enhanced oil recovery. Society of Petroleum Engineers, Richardson, pp 17-18, 237-241

Maroto-Valer MM (2010) Developments and innovation in carbon dioxide $\left(\mathrm{CO}_{2}\right)$ capture and storage technology. Woodhead Publishing, Boca Raton, p 116

Mashayekhizadeh V, Kord S, Dejam M (2014) EOR potential within Iran. Special topics and reviews in porous media. Int $\mathbf{J}$ 5(4):325-354

Olayiwola SO, Dejam M (2019a) A comprehensive review on interaction of nanoparticles with low salinity water and surfactant for enhanced oil recovery in sandstone and carbonate reservoirs. Fuel 241:1045-1057

Olayiwola SO, Dejam M (2019b) Mathematical modelling of surface tension of nanoparticles in electrolyte solutions. Chem Eng Sci $197: 345-356$
Orr FM Jr, Taber JJ (1984) The use of $\mathrm{CO}_{2}$ in enhanced oil recovery. Science 224:563-579

Pizarro JOS, Branco CCM (2012) Challenges in implementing an EOR project in the Pre-salt Province in deep offshore Brazil. In: EOR conference at oil and gas west Asia, 16-18 April 2012. Society of Petroleum Engineers (SPE), Muskat, Paper SPE 155665

Riccomini C, SantAna LG, Tassinari CCG (2012) Pré-sal: geologia e exploração. Revista USP 95:33-42

Rostami P, Mehraban MF, Sharifi M, Dejam M, Ayatollahi S (2019) Effect of water salinity on oil/brine interfacial behavior during low salinity waterflooding: a mechanistic study. Petroleum 5:367-374

Salomão MC, Marçon DR, Rosa MB, Salles Pessoa TC, Pinto ACC (2015) Broad strategy to face with complex reservoirs: expressive results of production in Pre-salt area offshore Brazil. In: Offshore technology conference (OTC), 4-7 May 2015. OTC, Houston, Paper OTC-25712-MS

Shell do Brasil (Shell) (2016) Libra. Shell Publishing. http://www. shell.com.br/sobre-a-shell/nossos-negocios/libra.html. Accessed 20 January 2019

Szatmari P (2000) Habitat of petroleum along the South Atlantic margins. In: Mello MR, Katz BJ (eds) Petroleum systems of South Atlantic margins. American Association of Petroleum Geologists, memoir 2000 73: 69-75

Taber JJ, Martin FD, Seright RS (1996) EOR screening criteria revisited: Part 1-introduction to screening criteria and enhanced recovery field projects. In: Improved oil recovery symposium, 21-24 April 1996. Society of Petroleum Engineers (SPE)/US Department of Energy (DOE), Tulsa, Paper SPE 35385

US Department of Energy (DOE) (2020) Enhanced oil recovery: office of fossil energy. DOE Publishing, DOE, Washington. http://energ y.gov/fe/science-innovation/oil-gas-research/enhanced-oil-recov ery. Accessed 06 August 2020

Publisher's note Springer Nature remains neutral with regard to jurisdictional claims in published maps and institutional affiliations. 